\title{
HYPOMAGNESEMIC TETANY IN CAMEL CALVES (CAMELUS DROMEDARIUS): CLINICAL CONSEQUENCES AND TREATMENT OUTCOMES
}

\author{
Sherif M. Shoeib ${ }^{1}$, Mohamed Z. Sayed-Ahmed ${ }^{2,3}$, Sabry A. El-khodery²*
}

${ }^{1}$ VeterinaryTeaching Hospital,FacultyofVeterinaryMedicine,MansouraUniversity, Mansoura 35516, Egypt, ${ }^{2}$ Department of Internal Medicine and Infectious Diseases, Faculty of Veterinary Medicine, Mansoura University, Mansour 35516, Egypt, ${ }^{3}$ Department of Clinical Pharmacy, College of Pharmacy, Jazan University, Jizan45142, Saudi Arabia

*Corresponding author, E-mail: khodery@mans.edu.eg

\begin{abstract}
Camels are the top herds wealth in Saudi Arabia, since is considered as heavy animal population, breeding resist more dangerous diseases. This clinical study was delineated to explain the clinical presentation of hypomagnesaemia in camel calves and to evaluate the efficacy of treatment with magenesium therapy. The investigation was performed in central Saudi Arabia during the period from November 2017 to October 2018. Twenty-seven dromedary camels, 3-6months of age were included in this study on the basis of clinical and treatment outcomes during the period from November 2017 to October 2018. Animals were allocated to two groups, the first group $(n=5)$ was considered as healthy (control) animals. The second group $(n=22)$ was clinically showing signs of hypomagnesemis. Allanimals were subjected to biochemical analysis of serum and ruminal fluid. Therapeutic response of the clinically affected animals was assessed after intravenous injection of $100 \mathrm{ml}$ calcium-magnesium preparation intramuscularly. injection of $10 \mathrm{ml}$ Vitamin B complex, and oral administration of $2 \mathrm{gm} \mathrm{Mg}$ sulphate orally for five consecutive days. Clinically affected camels revealed tetany, star gazing, episodes of convulsions with erected ears and tail, extension of head and neck, widening and dilatation of nares. Serum and ruminal fluid analysis revealed a significant decreased $(p<0.05)$ in $\mathrm{Mg}, \mathrm{Ca}$, and Phosphorus $(\mathrm{P})$ in clinically affected cases compared to control and treated groups. Total protein (TP), globulin, albumin, , urea and creatinine were significantly higher in clinical cases compared to treated cases. In conclusion, the hypomagnesemic tetany had a high occurrence in camel calves 3-6 month of age. Furthermore, the treatment regieme of hypomagnesemic tetany had agood threrapeutic response.
\end{abstract}

Key words: biochemical tests; camel calves; hypomagnesemic tetany; Saudi Arabia

\section{Introduction}

Hypomagnesemic tetany is a metabolic disorder that occurs in a wide range of nutritional disorders in ruminants (1). Magnesium deficiency results from a reduced ability of the 
calves to absorb dietary magnesium as exogenous dietary supply (2).

Magnesium homeostasis mainly depends on its absorption from gastrointestinal tract, bioavailability and requirement for milk, but not on a hormonal feedback system. Any extra $\mathrm{Mg}$ is excreted via urine. Reduced $\mathrm{Mg}$ absorption from the rumen may explain the insufficient inflow $(3,4)$.Consequently, the level of magnesium in the blood and extracellular fluid depends onthe balance between input and output (4).

The calves affected have concurrent hypocalcemia, as they fed milk with low magnesium $(\mathrm{Mg})$ concentration. The camel calves fed with only milk, will be insufficient to maintain the balance of $\mathrm{Mg}$ and calcium (Ca). In lactating mothers and their camel calves, higher serum values of aluminum (Al) and lower values of $\mathrm{Mg}$ were observed compared to other groups. It is suggested that the increase in serum $\mathrm{Al}$ in calves might be due to feeding Al-rich milk and that the decline in $\mathrm{Mg}$ concentration might be a consequence of $\mathrm{Al}$ and increased secretion of parathyroid hormone (5). The efficiency of absorption during intestinal transit is reduced in cases of diarrhea (4).

Mild neurological signs with increased excitability occur when there is a critical decrease in the serum $\mathrm{Mg}$ level. However, animal may not show clinical signs, although there is low serum Mg level (6). Ingestion of green grasses caused high rumen $\mathrm{pH}$, with subsequent reduction of Mg absorption (7).

The most famous clinical signs of hypomagnesemic tetany are represented by excitations and muscle cramps, which are strongly interrelated with the concentration of $\mathrm{Mg}$ in the cerebrospinal fluid. It is suggested that the neurological signs of hypomagnesaemia are induced by activation of neurons in the cerebrospinal fluid (3). Therefore, the present study describes clinical consequences and successful management of hypomagnesemic tetany in camel calves.

\section{Materials and methods}

Study area

This clinical study was carried out in central Saudi Arabia (Al-Qassim, Hermla and Shaqra). Each farm was visited twice monthly to explore the presence of clinical disease.

Animals and study design

A total of 27 camel calves with age range from 2-6 months were investigated clinically and biochemically from November 2016 to April 2017. 22 camels had history of nervous signs such as tetany, convulsion, ataxia, staggering gait, muscular tremors and inability to stand up. Most of the clinical cases were recorded in winter and spring seasons. All the clinically affected animals were treated with $\mathrm{Mg}$ therapy as mentioned below.

\section{Clinical examination}

All calves in the control, and clinical groups were clinically examined as previously documented (4).

\section{Serum sampling and biochemical analysis}

Blood samples from control and diseased calves were obtained from the jugular vein and collected into sterile tubes without anti-coagulant. Serum was obtained and stored at $-80^{\circ} \mathrm{C}$ till analysis. Serum biochemistry was conducted using commercial kits (Bio- Mureix) for spectrophotometric determination of $\mathrm{Mg}, \mathrm{P}$, albumin, calcium, potassium, Aluminium, urea nitrogen, and creatinine (8-15), Globulin and Albumin/Globulin ratio were calculated.The parathyroid hormone was measured by radioimmunoassay (16).

\section{Ruminal fluid collection and analysis}

Ruminal samples were collected by stomach tube from each animal. The samples were centrifuged at $3000 \mathrm{rpm}$ for 15 minutes. The supernatant layer was transferred to a clean tube and keep in deep freezer for spectrophotometric determination of $\mathrm{Mg}, \mathrm{Ca}$, and $\mathrm{P}$ using commercial kits (Bio-morieux) and spectrophotometer (spin lab, Spinreact S.A. Model 2003) as previously described (17). 
Assessment of therapeutic response

Therapeutic response of the clinical cases was assessed after a five day treatment with IV injection of $100 \mathrm{ml}$ calcium magnesium borogluconate (Cal-Bor-Mag, kela Pharamceuticals, belgium) daily. In addition, $10 \mathrm{ml}$ of Vitamin B complex (corobral, Vetoqunol, france) was given IM and $2 \mathrm{gm} \mathrm{Mg}$ sulphate were given orally for 5 days (18).

\section{Statistical analysis}

Statistical assessment of the clinical parameters, biochemical findings of the control group and of hypomagnesemic calves before and after treatment were done using SPSS Ver. 16.0 package program with Student's paired-t test as previously described (14). All data were given as Mean \pm SEM, and results were considered significant at $\mathrm{P}<0.05$.
All the twenty -two animals from twelve different herds in the area were found to express nervous manifestations such as tetany, convulsion, ataxia, staggering gait, muscular tremors and inability to stand up (Fig.1). There was also tachypnea, tachycardia and mild elevation of rectal temperature.

Clinicopathological findingsshowed a significant $(\mathrm{P}<0.05)$ decrease in the serum values of $\mathrm{Mg}$ in camels calves before treatment $(0.89 \pm 0.09 \mathrm{mmol} / \mathrm{L})$ compared with treated camel calves $(1.3 \pm 0.2 \mathrm{mmol} / \mathrm{L})$. The other examined parameters remained within the normal average in both diseased and normal camels (P $>0.05)$. Ruminal fluid analysis showed a significant reduction $(\mathrm{P}<0.05)$ in $\mathrm{Mg}, \mathrm{Ca}$ and $\mathrm{P}$ in hypomagnesemic tetany camel calves compared to control animals (Table $1 \& 2$ ).

\section{Results}

Table 1: Serum biochemical parameters (Mean \pm SE) of camel calves with hypomagnesemic tetany before and after treatment

\begin{tabular}{llll}
\hline Parameter & Control & Diseases & Treated \\
\hline Calcium (mmol/L) & $2.6 \pm 0.18$ & $2.31 \pm 0.3$ & $2.5 \pm 0.4$ \\
Chloride (mmol/L) & $110.9 \pm 1.3$ & $121.5 \pm 1.4$ & $112.2 \pm 1.5$ \\
Cupper (mmol/L) & $82.5 \pm 1.5$ & $67.2 \pm 2.1$ & $76.6 \pm 1.5$ \\
Phosphorus (mmol/L) & $2.44 \pm 0.14$ & $2.25 \pm 0.3$ & $5.7 \pm 0.2$ \\
Magnesium (mmol/L) & $1.27 \pm 0.17$ & $0.89 \pm 0.09^{*}$ & $1.3 \pm 0.2$ \\
Aluminium & $2.4 \pm 0.17$ & $5.4 \pm 0.23$ & $2.8 \pm 0.07$ \\
Zink (mmol/L) & $57.8 \pm 1.6$ & $62.6 \pm 2.1$ & $52.6 \pm 1.4$ \\
Total protein (g/L) & $66.4 \pm 0.2$ & $80.1 \pm 0.28$ & $76 \pm 0.2$ \\
Albumin (g/L) & $38.4 \pm 0.08$ & $38.1 \pm 0.13$ & $34 \pm 0.1$ \\
Globulin $(\mathrm{g} / \mathrm{L})$ & $28 \pm 0.2$ & $42 \pm 0.15$ & $42 \pm 0.16$ \\
Urea(mg/dl) & $24.9 \pm 0.2$ & $22.07 \pm 0.5$ & $22.07 \pm 0.4$ \\
Creatinine (mg/dl) & $1.8 \pm 0.1$ & $1.3 \pm 0.05$ & $1.3 \pm 0.07$ \\
\hline
\end{tabular}

*: means significantly different at $\mathrm{p}<0.05$

Table 2: Calcium, phosphorus and magnesium in ruminal fluid analysis (Mean $\pm \mathrm{SE}$ ) of camel calves with hypomagnesemic tetany befor and after treatment

\begin{tabular}{llll}
\hline Parameter & Control & Before treat & After treat \\
\hline $\mathrm{Mg}(\mathrm{mmol} / \mathrm{L})$ & $1.23 \pm 0.4$ & $0.98 \pm 0.40^{*}$ & $1.2 \pm 0.5$ \\
$\mathrm{Ca}(\mathrm{mmol} / \mathrm{L})$ & $2.8 \pm 0.17$ & $1.6 \pm 0.21^{*}$ & $2.84 \pm 0.4$ \\
$\mathrm{P}(\mathrm{mmol} / \mathrm{L})$ & $1.81 \pm 0.12$ & $1.5 \pm 0.05^{*}$ & $1.8 \pm 0.03$ \\
\hline
\end{tabular}

*: means significantly different at $\mathrm{p}<0.0$ 

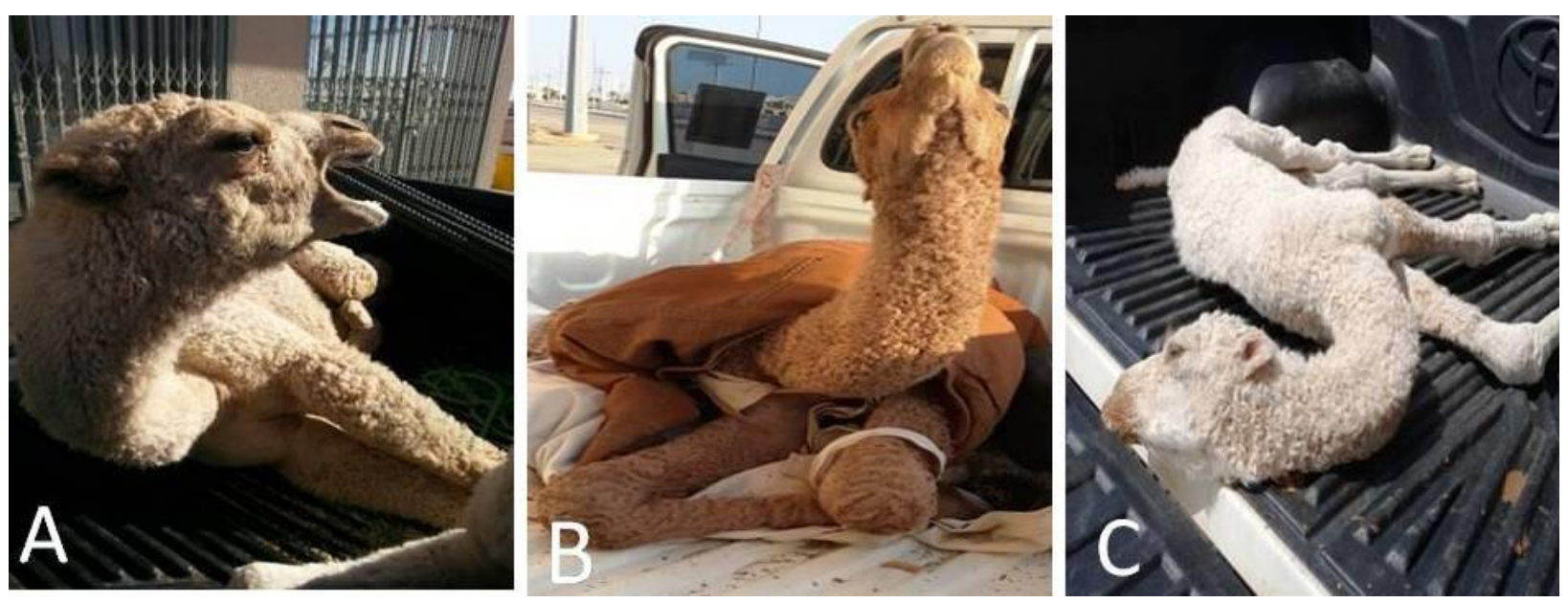

Figure 1: A camel calves suffered from hypomagnesemictetany showing nervous signs (A), tetanic convulsion and recumbency (B), and star gazing and staggering gait (C)

\section{Discussion}

Diseases that cause neurological signs in animals are many and are usually caused by a variety of agents including viruses, parasites, bacteria, neuro-toxic chemicals and plant poisons as well as genetic abnormalities and nutritional deficiencies (19).Clinical findings of clinical hypomagnesemia in camel calves were tetanic convulsions, opisthotonos, star gazing, episodes of convulsions with erected ears, extension of head and neck, erected tail, widening and rotation of the eye ball and dilatation of nares, similar findings were recorded previously $(18,20)$.

It has been demonstrated that slow type of hypomagnesemic tetany is diagnosed in cows for several months, especially during cold season. Critical reduction of $\mathrm{Mg}$ levels in the plasma is usually accompanied by clinical signs of hyperirritability and incoordination. Hypomagnesemic tetany is termed the winter tetany, associated with low dietary $\mathrm{Mg}$, low quality of feeds and environmental stresses (21).The clinical parameters showed a significant increase $(\mathrm{P}<0.05)$ in the heart and respiratory rates in hypomagnesemic cases than control. Body temperature showed mild increased in hypomagnesemic cases compared to control and treated cases. However, ruminal motility was significantly decreased than control. These results were similar to those recorded in previous stud- ies $(20,22,23)$. The imbalance between calcium and magnesium ratio in extra and intracellular fluid might induce the abnormal function of nerve fibers in peripheral and/or central nervous system, which lead to increase in heart rate and rapid respiration (24). The reduction of ruminal motility in diseased cases could be attributed to the biological role of $\mathrm{Mg}$ in maintaining the ruminal contractions (3). The clinical identification of hypomagnesaemia is usually made by a combination of clinical history, signs and response to $\mathrm{Mg}$ therapy. The clinical signs rapidly progress and death occurs within few hours, but most of animals with hypomagnesaemia may found dead (25). In most cases, low dietary magnesium intake not only produces clinical signs, but also may need other predisposing factors. In the present study the $\mathrm{Mg}$ level was reduced to $0.89 \mathrm{mg} / \mathrm{dl}$ in clinical tetanic cases. The hyperesthesia, the tetany and convulsion in hypomagnesaemia could be attributed to the central effect or the disturbance in the neuromuscular junction due to $\mathrm{Mg} / \mathrm{Ca}$ deficiency (26). This study showed marked increase in aluminum in camel calves with tetany. It has been demonstrated that increase in serum Al in calves might be due to feeding Al-rich milk and that the decline in $\mathrm{Mg}$ concentration might be a consequence of $\mathrm{Al}$ and increased secretion of parathyroid hormone (5).Moreover, release of adrenal glucocorticoid as a result of stress reaction, causes increased circulating level of $\mathrm{K}$ and decrease $\mathrm{Mg}$ transport across the 
choroidal plexus, with subsequent appearance of the neurological signs (27). Another pathway is that, the decrease of energy intake inhibits the rumen fermentation process, with subsequent decrease of volatile fatty acids and $\mathrm{CO}_{2}$ concentrations and increase of ammonia concentration. The decrease of energy intake can also increase the rumen $\mathrm{pH}$ due to high ammonia and low volatile fatty acid with eventual reduction of the mg absorption (3).

The increased urea level in diseased cases has been observed also in other studies (29). Anorexia and starvation associated with the disease causes protein catabolism and consequently retention of nitrogenous wastes (6). In ruminants, it is known that when there is low protein intake, animals can diminish their urinary urea loss, and increase the availability of nitrogen required for protein synthesis in the rumen. (30).

Ruminal fluid showed a significant reduction $(\mathrm{P}<0.05)$ in $\mathrm{Mg}, \mathrm{Ca}$ and $\mathrm{P}$ in hypomagnesemic tetany camel calves compared to control These results were comparable to those recorded in goats with experimentally-induced hypomagnesaemia (29). The Mg concentration in the diet is a major determinant of it concentration in the ruminal fluid (31). Therefore, the low $\mathrm{Mg}$ in ruminal fluid could be attributed to low $\mathrm{Mg}$ intake, which consequently leads to low serum $\mathrm{Mg}$ levels. In young calves, it has been known that $\mathrm{Mg}$ is absorbed efficiently from the small intestine. But, when the rumen and reticulum are well developed, they are the main site of absorption. (32). The absorption of $\mathrm{Mg}$ through ruminal wall depends on its concentration in the ruminal fluid and efficacy of $\mathrm{Mg}$ transport action (31). There are 2 mechanisms for $\mathrm{Mg}$ absorption from rumen epithelium, the active and passive mechanisms. Active transport of $\mathrm{Mg}$ across the rumen wall is necessary when $\mathrm{Mg}$ in supplement in diet is little, active transport of the $\mathrm{Mg}$ crosswise the wal of rumen is of great importance. However, when there is high rumen fluid $\mathrm{Mg}$, passive transport occurs. Passive transport of $\mathrm{Mg}$ allow decrease of concentration gradient into the extracellular fluid (3).The minimum ruminal fluid $\mathrm{Mg}$ level that activates the passive mechanism is 9.2 $\mathrm{mg} / \mathrm{dl}$ (33). Because the $\mathrm{Mg}$ concentration in ruminal fluid of clinical hypomagnesemia was lower than that level, the passive transport mechanism of $\mathrm{Mg}$ is inactivated.

In conclusion, the results of our investigation indicate that hypomagnesaemia exists in camel calves and it should be considered when confronted with cases showing nervous manifestations.

\section{Conflict of interest}

There is no conflict of interest

\section{References}

1. Smith RA and Edward WC. Hypomanesemictetany of ruminants.Vet Clin North Am Food AnimPract.1988; 4(2):365-77.

2. Smith RH. Importance of magnesium in the control of plasma calcium in the calf. Nature,1961; 191: 181-2.

3. Martens H and Schwigel M. Pathophysiology of grass tetany and other hypomagnesiumias.Implication for clinical management Vet Clin North Am Food AnimPract2000; 16 (2):339-8.

4. Radostits OM, Gay CC, Hinchcliff KW, Constable PD. Veterinary Medicine: a textbook of the diseases of cattle, horses, sheep, pig and goats.2010; $10^{\text {th }}$ Ed. B. Saunders, London, New York, Philadelphia, Sydney and Toronto.

5. Khaled A Al-Busadah. Serum Concentration of Aluminum, Calcium, Magnesium and Phosphorous in Camels Scientific Journal of King Faisal University (Basic and Applied Sciences) 2010; 11 (1): 1431

6. Hoff B, Rognmo A, Havre G, Morberg H. Seasonal Hypomagnesemia in reindeer on Kautokeino winter pasture in Finnmark County, Norway. Rangifer1993; 13 (3): 133-6.

7. Parkinson TJ, Vermunt JJ, Malmo J. Disorders of magnesium metabolism. Diseases of cattle in Australasia. New Zealand Veterinary Association Foundation for Continuing Learning2010; 532-41.

8. Fischbach FT, Dunning MB: Manual of Laboratory and Diagnostic Tests, 8th ed. Philadelphia: 2009; Lippincott Williams and Wilkins.

9. Burtis C, and Bruns DTietz Fundamentals of Clinical Chemistry. 6th ed. WB. Saunder Co., Philadelphia, USA 2007.

10. Henry RF, Cannon DC and Winkelman JW. Clinical Chemistry Princepals 2nd. Ed.harper and Roe, Hagerstown, MD. Hoff, B.; Rognmo, A.; Havre, G. and Morberg, H. (1993): Seasonal Hypo- 
magnesemia in reindeer on Kautokeino winter pasture in Finnmark County, Norway. Rangifer1974; 13 (3): 133-136.

11. Young DS. Effect of drugs on clinical Laboratory tests, 3rd Edition. AACC Press, Washington, D.C.1990; pp. 3122-31.

12. Chernecky CC and Berger BJ: Laboratory Tests and Diagnostic Procedures, $5^{\text {th }}$ d. St.Louis: Saunders2008.

13. Thefeld W: Annuals of Clinical Biochemistry. Cited by: Wooton and Freemon 1974;pp.79.

14. Ozkan C, Altug N, Yuksek N, Kaya A, Akgul Y. Assessment of lectrocardiographic findings, serum nitric oxide, cardiac troponins and some enzymes in calves with hyperkaliemia related to neonatal diarrhea. Revue MédVét 2011; 162 (4): 171176.

15. Pagana KD and Pagana TJ. Mosby's Manual of Diagnostic and Laboratory Tests $4^{\text {th }}$ ed. St. Louis: 2010; Mosby Elsevier.

16. Mayer GP, Hurst JG, Barto JA, Keaton JA, Moor MP. Effect of epinephrine" on PTH hormone secretion in calves. Endocrinol1979; 104: 1181-7.

17. Reynolds CK, Bell MC, Sims MH. Changes in Plasma, Red Blood Cell and cere- brospinal fluid Mineral Concentrations in Calves during Magnesium Depletion Followed by Reple- tion with Rectally Infused Magnesium Chloride. J Nutr.1984; 114: 1334-41.

18. Naik SG, Ananda KJ, Rani BK. Magnesium deficiency in young calves and its management. Veterinary World.2010;3(4): 192-3.

19. Al-Dubaib MA, Al-SwailemA, AlGhamdiG, Al-YamaniE, Al-NaeemAA, AlMejaliAM, ShehataM, HashadM, El-LithyDA, MahmoudOM.Dubduba syndrome: A new neurological disease of camels with a possible viral etiologic agent. J Camel Prac Res 2008; 15: 147-2.

20. Attia MT. Some studies on hypomagnesemia in calves under natural and experimental conditions.MVSc1999; Thesis, Faculty of Veterinary Medicine, Zagazig University, Egypt.

21. Matsui T. Significance of Magnesium in Animals. New Perspectives in Magnesium Res 2007; 13: 381-91.

22. Mills J. Hypomagnesemia in calves. Vet. Rec. 131: 3. Morris, M.E.: Brain and CSF magne sium concentrations during magnesium deficit in animals and humans: neurological symptoms. Magnes Res 1992; 5(4): 303-13.

23. Jayanthi M, Sundar SN, Karunandhi PS, Chaudhuri PC. Serum biochemical findings in experimental hypomagnesemia in buffaloe calves. Indian Vet J 1997; 14 (9): 752-4.

24. Shiga A, Keino M, Fujio O. Experimental studies on hypomagnesemia in ruminants: effects of varying calcium content in low-magnesium diets in serum concentration of magnesium and calcium and heart rate in lactating ewes. Jpn J Vet Sci1983; 45 (4): 435-42.

25. McCoy MM.Hypomagnesemia and new data on vitreous humour magnesium concentration as a post-mortem marker in ruminants. Magnesium Res2004; 17 (2): 137-45.

26. Morris ME. Brain and CSF magnesium concentrations during magnesium deficit in animals and humans: neurological symptoms. Magnes Res1992; 5(4): 303-13.

27. Robson AB, Sykes AR, McKinnon AE, Bell ST. A model of magnesium metabolism in young sheep: transactions between plasma, cerebrospinal fluid and bone. Br J Nutr 2004; 91: 73-9.

28. El-Sangary FH, El-Barawy, AM, Faris A, ElHamied SSA.Hypomagnesemia in beef calves at its relation with parathyroid hormonelevel.Assiut Vet Med J 2011; 57 (131): 300-11.

29. Washia NM. Study on Hypomagnesaemictetany in goats. MVSc2007; Thesis, Faculty of Vet. Medicine, Alexandria University, Egypt.

30. Kaneko JJ. Clinical Biochemistry of Domestic Animals.1989; Ed. J. J. Kaneko, Academic Press Inc., New York.

31. Goff JP. The monitoring, prevention, and treat- ment of milk fever and subclinical hypocalcemia in dairy cows. Vet J 2008; 176: 50-7.

32. Dua K and Care AD. Impaired absorption of magnesium in the aetiology of grass Tetany. British Vet J1995;151:413-6.

33. Ram L, Schonewille, JT, Martens H, van'tKlooster AT Beynen AC. Magnesium absorption by wethers fed potassium bicarbonate in combination with different dietary magnesium concentrations. J Dairy Sci. 1998; 81: 2485-92. 